\title{
Modeling of Thermal Conductivity in a Medium with Phase Transition with a Moving Boundary of Phase Change
}

\author{
Mizonov V.E., Tikhonov A.I., Basova E.V., Mitrofanov A.V. \\ Ivanovo State Power Engineering University \\ Ivanovo, Russian Federation
}

\begin{abstract}
This work is devoted to the theoretical study of the effect of the phase interface motion on thermal conductivity in a liquid-solid nonlinear medium with a phase transition. The problem under consideration deals with the Stefan problems. Its most significant feature is the jump in the phase properties at separation of their moving boundaries. The objective was achieved by solving the following tasks: the construction of the process mathematical model based on its cell representation and with the use of the Markov chain theory mathematical apparatus, performing numerical experiments with the developed model, demonstrating its operability and the possibility to achieve the set goal. The most significant scientific results were as follows. First was an algorithm for the construction of a cell mathematical model of nonlinear thermal conductivity in a phase transitions medium with a moving phase interface for domains of a canonical shape (plane wall, cylinder, ball). Second, the results of the numerical experiments, showing that the jump of properties affected greatly the kinetics of the process. The significance of the results obtained consisted in the development of a simple but informative mathematical model of the media heat treatment kinetics with phase transformations, available for a direct use in the engineering practice. The proposed algorithm for constructing the model can be effectively used in prediction the open water pipes freezing in cold regions, in modeling the heat treatment of metals, in choosing the freezing modes of food products for a long-term storage, and other thermo-physical processes.

Keywords: nonlinear thermal conductivity, phase transition, phase interface, thermo-physical properties of phases, cell model, state vector, thermal conductivity matrix, numerical experiment.
\end{abstract}

DOI: https://doi.org/10.52254/1857-0070.2021.3-51.05

UDC: 536.2.02

Simularea conductivităţii termice într-un mediu de tranziție de fază cu o interfață de mișcare de faze Mizonov V.E., Tihonov A.I., Basova E.V., Mitrofanov A.V.

Universitatea Națională de energetică din Ivanovo Ivanovo, Federația Rusă

Rezumat. Scopul lucrării este de a studia teoretic efectul mișcării limitei fazei asupra conductivității termice întrun mediu neliniar lichid-solid cu tranziție de fază. Problema luată în considerare este una dintre variantele problemei lui Stefan. Cea mai importantă caracteristică a sa este un salt în proprietățile fazelor la limita separării lor, unde limita se mișcă pe măsură ce procesul continuă. Acest obiectiv este atins prin rezolvarea următoarelor sarcini: construirea unui model matematic al procesului bazat pe reprezentarea sa celulară şi utilizarea aparatului matematic al teoriei lanțurilor Markov, efectuarea experimentelor numerice cu modelul dezvoltat, demonstrând performanța acestuia și posibilitatea realizării obiectivul stabilit. Cele mai semnificative rezultate științifice sunt: un algoritm pentru construirea unui model matematic celular de conductivitate a căldurii neliniare într-un mediu cu tranziţii de fază cu o interfaţă mobilă pentru domenii canonice (perete plat, cilindru, bilă), rezultatele experimentelor numerice care arată că considerarea de saltul proprietăților la limita mobilă de separare are un efect semnificativ asupra cineticii procesului. Semnificația rezultatelor obținute constă în dezvoltarea unui model matematic simplu, dar informativ, al cineticii tratamentului termic al mediilor, în cadrul căruia au loc tranziții de fază cu o limită de fază în mișcare, care este disponibilă pentru utilizare directă în practica inginerească. Ținând cont de variabilitatea proprietăților la limita de mișcare a tranziției de fază crește precizia prezicerii stării procesului, dar, în mod firesc, această creștere depinde de cât de puternic diferă proprietățile fazelor. Modelul poate fi ușor adaptat pentru a descrie conductivitatea termică neliniară în medii multistrat.

Cuvinte-cheie: conductivitate termică neliniară, tranziție de fază, limită fazei, proprietăți termofizice ale fazelor, model de celule, vector de stare, matrice de conductivitate termică, experiment numeric.

(C) В.Е. Мизонов, А.И. Тихонов,

Е.В. Басова, А.В. Митрофанов, 2021 


\section{Моделирование теплопроводности в среде с фазовым переходом с подвижной границей раздела фаз Мизонов В.Е., Тихонов А.И., Басова Е.В., Митрофанов А.В. \\ Ивановский государственный энергетический университет \\ Иваново, Российская Федерация}

Аннотация. Цель работы заключается в теоретическом исследовании влияния движения границы раздела фаз на теплопроводность в нелинейной среде жидкость-твердое с фазовым переходом. Рассматриваемая задача является одним из вариантов задачи Стефана. Ее наиболее существенной особенностью является скачок свойств фаз на границе их разделения, где граница перемещается по мере протекания процесса. Поставленная цель достигается путем решения следующих задач: построение математической модели процесса на основе его ячеечного представления и использования математического аппарата теории цепей Маркова, выполнение численных экспериментов с разработанной моделью, демонстрирующих ее работоспособность и возможность достижения поставленной цели. Наиболее существенными научными результатами являются: алгоритм построения ячеечной математической модели нелинейной теплопроводности в среде с фазовыми переходами с движущейся границей раздела фаз для доменов канонической формы (плоская стенка, цилиндр, шар), результаты численных экспериментов, показывающие, что учет скачка свойств на движущейся границе разделения оказывает существенное влияние на кинетику протекания процесса. Значимость полученных результатов состоит в разработке простой, но информативной математической модели кинетики термической обработки сред, внутри которых протекают фазовые переходы с перемещающейся границей раздела фаз, доступной для непосредственного использования в инженерной практике. Учет переменности свойств на движущейся границе фазового перехода повышает точность прогнозирования состояния процесса, но, естественно, это повышение зависит от того, насколько сильно отличаются свойства фаз. Предложенный алгоритм построения модели может эффективно применяться при прогнозировании промерзания открытых водопроводных и иных труб для перекачки жидкости в холодных регионах, при моделировании термической обработки металлов и других материалов, при выборе режимов замораживания пищевых продуктов для длительного хранения и многих других теплофизических процессов. Модель может быть легко адаптирована к описанию нелинейной теплопроводности в многослойных средах.

Ключевые слова: нелинейная теплопроводность, фазовый переход, граница раздела фаз, теплофизические свойства фаз, ячеечная модель, вектор состояния, матрица теплопроводности, численный эксперимент.

\section{ВВЕДЕНИЕ}

Настоящее исследование посвящено проблеме влияния движение границы раздела фаз на теплопроводность в среде с переменными свойствами и фазовыми переходами. Задачи, связанные с нелинейной теплопроводностью, возникают при моделировании и расчете многих теплофизических процессов в энергетике, химической, строительной, пищевой промышленности и других отраслях. Во многих технологических процессах перенос теплоты теплопроводностью осложнен сопутствующими процессами внутри теплопроводящей среды, например, фазовыми переходами, химическими реакциями, перемещающимися локальными источниками теплоты и другими. Кроме того, структура среды, в которой протекает процесс, может быть неоднородной (многослойной) и изменяться в течение процесса. Поставленная задача решается методом математического моделирования. При этом должны быть объединены модели собственно теплопроводности, рассчитываемой по локальным параметрам состояния, модели зависимости коэффициентов переноса от локальных параметров состояния и модели фазовых переходов. Ниже приведен краткий обзор литературных источников, относящихся к решаемой задаче.

Известны многочисленные работы по построению аналитических решений уравнения теплопроводности с упомянутыми и иными ограничениями, которые, однако, связаны с далеко идущими упрощениями, часто ограничивающими возможность практического применения получаемых решений. Некоторые аналитические решения представлены в работах [1-9]. В работе [1] уравнение теплопроводности в плоской стене здания решается для переменной внешней и внутренней температуры путем разложения графиков этих температур в ряд Фурье. Очевидно, что такое решение представляет чисто академический интерес, так как ни неоднородность структуры стенки, ни возможность фазовых переходов влаги внутри нее этим подходом учтены быть не могут. То же можно сказать о результатах работы [2,3], в которой использован метод интегрального преобразования Лапласа. В то же время в статье [4] подчеркнуто, что, как правило, внешние слои стен 
зданий претерпевают в зимнее время замерзание и оттаивание в них влаги, что приводит к снижению их термического сопротивления на 7\% и более и что неадекватно принимать их теплофизические свойства постоянными. В работах [5-7] отмечено, что при отрицательных окружающих температурах неоднородность структуры стенки часто приводит к локальному промерзанию влаги и образованию так называемых термических мостиков. По ним происходит более интенсивный теплоперенос, в результате чего термическое сопротивление стенки может превосходить на $25 \%$ и более по сравнению с расчетом без учета формирования этих мостиков. В работе [7] описан новый метод теплового моделирования двух- и трехмерных структур с использованием для описания тепловых процессов пространство теплового состояния, что является, на наш взгляд, интересным и продуктивным. Однако, предложенный метод не предполагает моделирование фазовых переходов. В статьях $[8,9]$ рассмотрены аналитические модели распространения теплоты доменах различной конфигурации, прогреваемых локальными перемещающимися источниками теплоты, но здесь также не рассматриваются фазовые переходы и/или химические реакции внутри доменов. Работа [10] относится к устойчивости установившихся решений при линейной и нелинейной теплопроводности. Показано, что при нелинейной теплопроводности только одно решение является устойчивым к возмущениям краевых условий. Эта работа обращает внимание исследователей на необходимость обращать внимание на этот аспект проблемы.

Многие работы посвящены полуаналитическим и численным методам с тем, чтобы иметь возможность увеличивать размерность задач, а также оперировать с доменами сложной конфигурации. Например, в работе [11] предложен оригинальный полуаналитический метод расчета нестационарной теплопроводности в плоской стенке, в работе [12] использован интегральный метод расчета теплопроводности в составной среде, а в работе [13] метод учета фазового перехода. Однако, все предлагаемые в них решения носят частный характер и вряд ли применимы в инженерной практике. Статья [14] описывает достаточно общий подход к решению трехмерной обратной задачи теплопроводности, сочетающий метод функции комплексной переменной и метод граничных элементов. Однако и здесь метод расчета не сочетается с учетом фазовых переходов.

Статьи [15-19] описывают методику и результаты моделирования теплопроводности в неоднородных средах. Так в работе [15] описан трехмерный теплоперенос в трехслойной стенке хранилища ядерных отходов. Здесь использована комбинация методов Фурье и Лапласа, используя которые описать фазовый переход нельзя. В статье [16] решается задача теплопроводности в двухслойной среде с переменными теплофизическими свойствами, но размеры слоев заранее зафиксированы, а фазовый переход не учитывается. Работа [17] рассматривает задачу о трехмерной теплопроводности в функционально градуированной среде, решаемую гибридным численным методом, сочетающим метод конечных разностей и метод отложенной корректировки Крылова. Аналогичная задача, но только для установившегося распределения температуры, решается в работе [18] методом Галеркина. Обе работы не касаются фазовых переходов. Статья [19] рассматривает способы охарактеризовать фазовый переход с помощью экспериментального подхода с использованием обратной задачи теплопроводности, но эта интересная работа не попадает в контекст настоящего исследования.

Работы [20-22] являются примерами решения задач Стефана - задач с подвижными внешними и/или внутренними границами, перемещающимися или по заданному закону, или по мере влияния на них протекающего процесса. В статье [20] рассмотрена задача о теплопроводности в изначально дискретном многофазном материале. В качестве примера рассмотрен процесс остывания чугунного слитка на медной подложке. Моделирование теплопроводности в тающем слое снега на нагреваемой подложке описано работе в [21]. Здесь детально рассмотрены тепловые условия на границах слоя снега (высота слоя меняется по мере таяния), но сам слой представлен как локализованная систем, то есть термически тонкое тело. Наконец, в работе [22] моделируется рост маленького кристалла в растворе, где скорость роста зависит от теплового состояния растущего тела. Оно же, в свою очередь, зависит от теплопроводности в теле. Авторы заключают, что такая теплопроводность носит неклассический характер.

Анализ перечисленных исследований показывает, что до сих пор не выполнен желаемый синтез моделей собственно теплопро- 
водности и сопутствующих ей теплофизических процессов, например, фазовых переходов. Кроме того, методы построения моделей и их численной реализации часто радикально меняются при переходе от одной частной задачи к другой, что лишает их универсальности и доступности в инженерной практике.

Близкая проблематика затронута в работе [23], где рассматривается замораживание бурсита коленного сустава. Продвижение фронта промерзания относится к задаче Стефана, для решения которой предложен оригинальный метод, применимый, однако, только к рассматриваемой задаче.

В наших предыдущих исследованиях было предложено и обосновано применение теории цепей Маркова для моделирования процессов переноса. Этот подход доказал свою эффективность при описании механических (измельчение, смешивание, кипящий слой) и тепловых (теплоперенос в дисперсных средах, химические реакции в твердых частицах) процессов.

Таким образом, целью настоящего исследования является построение ячеечной математической модели теплопроводности в среде с фазовыми переходами, описывающей продвижение фронта фазового перехода, и его влияние на общие характеристики процесса.

\section{МЕТОДЫ, РЕЗУЛЬТАТЫ И ОБСУЖДЕНИЕ}

Не нарушая общности алгоритма построения математической модели, рассмотрим его на частном примере замерзания жидкости в одном из объемов канонической формы, показанных на рис.1: в плоской стенке (a), в цилиндре (b) и шаре (c).

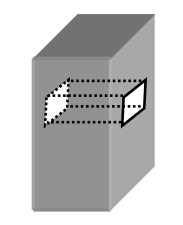

d) a)

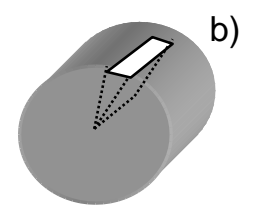

c)

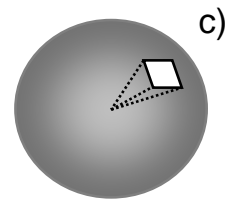

Фазовый переход (Phase transform) Перемена свойств (Change of properties)

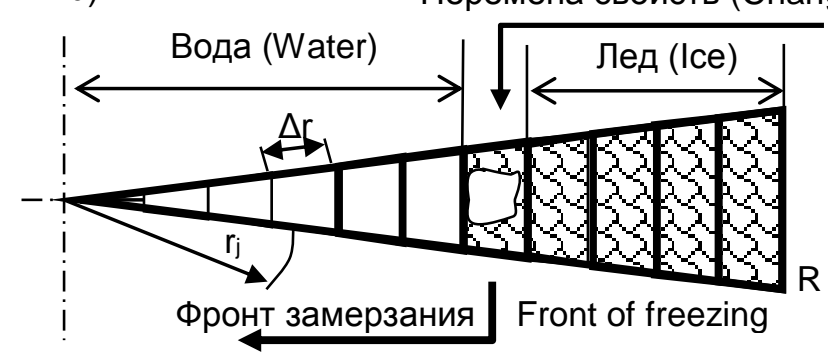

Рис.1. Моделируемые объемы канонической формы (a - плоская стенка, $\mathrm{b}$ - цилиндр, $\mathrm{c}$ - шар) и структура ячеечной модели (d). ${ }^{1}$

На рис.1d показан выделенный из объема домен, для которого и будет выполняться построение модели. Он разбит в радиальном направлении на $m$ ячеек одинаковой радиальной протяженности $\Delta r=R / m$, где $R$ внешний радиус домена. На этом радиусе от домена отводится теплота, в результате чего жидкость сначала охлаждается, а потом замерзает, причем фронт замерзания движется от периферии внутрь объема. Тепловые и фазовые характеристики процесса фиксируется в дискретные моменты времени $t_{k}$ разделенные одинаковыми малыми промежутками $\Delta t$. Тогда
$t_{k}=\Delta t(k-1)$, где $k-$ номер временного перехода, который может рассматриваться как дискретный аналог времени. Считается, что в каждый момент времени все параметры теплового и фазового состояния равномерно распределены по объему каждой индивидуальной ячейки. Распределение же свойств и параметров по ячейкам цепи представлено матрицами (векторами) столбцами: $\quad$ теплота $\quad \mathbf{Q}^{\mathbf{k}}=\left[Q_{j}^{k}, 1\right]$, температура $\mathbf{T}^{\mathbf{k}}=\left[T_{j}^{k}, 1\right]$, содержание жидкой 
фазы $\quad \mathbf{M}_{\mathbf{L}}{ }^{\mathbf{k}}=\left[M_{L j}{ }^{k}, 1\right], \quad$ теплопроводность $\lambda^{\mathbf{k}}=\left[\lambda_{j}^{k}, 1\right]$, плотность $\boldsymbol{\rho}^{\mathbf{k}}=\left[\rho_{j}^{k}, 1\right]$, удельная теплоемкость $\mathbf{c}^{\mathbf{k}}=\left[c_{j}^{k}, 1\right]$. Здесь $j-$ номер ячейки, отсчитываемый от центра.

Векторы состояния меняются с течением времени, то есть с переходом состояния $k$ в состояние $k+1$. Основной причиной этих изменений является перераспределение теплоты в объеме, которое осуществляется путем теплопроводности. Эволюция теплового состояния может быть описана рекуррентным матричным равенством

$$
\mathbf{Q}^{\mathrm{k}+1}=\mathbf{P}^{\mathrm{k}} \mathbf{Q}^{\mathrm{k}+1}
$$

где $\mathbf{P}^{\mathbf{k}}$ - матрица теплопроводности (матрица переходных вероятностей в терминах теории цепей Маркова). Элементы этой матрицы описывают доли теплоты, переносимой за один временной переход путем теплопроводности из данной ячейки в примыкающие к ней. Эти доли зависят от теплового и фазового состояния среды в ячейке и корректируются на каждом временном переходе, то есть матрица теплопроводности зависит от текущих векторов состояния, и задача является нелинейной. Матрица $\mathbf{P}$ является трехдиагональной матрицей и формально имеет следующий вид

$$
\mathbf{P}^{\mathrm{k}}=\left[\begin{array}{ccccc}
\ldots & \ldots & \ldots & \ldots & \ldots \\
\ldots & P_{j-2, j-1}^{k} & 0 & \ldots & \ldots \\
\ldots & P_{j-1, j-1}^{k} & P_{j-1, j}^{k} & 0 & \ldots \\
\ldots & P_{j, j-1}^{k} & P_{j, j}^{k} & P_{j j+1}^{k} & \ldots \\
\ldots & 0 & P_{j+1, j}^{k} & P_{j+1, j+1}^{k} & \ldots \\
\ldots & \ldots & 0 & P_{j+2, j+1}^{k} & \ldots \\
\ldots & \ldots & \ldots & \ldots & \ldots
\end{array}\right],
$$

где первый нижний индекс показывает, в какую ячейку переносится теплота, а второй - из какой.

Ранее нами из уравнений теплового баланса при одном временном переходе $\Delta t$ на основе уравнения теплопроводности Фурье были получены расчетные формулы для определения элементов этой переходной матрицы в следующем виде

$$
\begin{gathered}
P_{j, j+1}^{k}=\frac{\lambda_{j+1}^{k}}{c_{j+1}^{k} \rho_{j+1}^{k}}\left(1-\frac{\Delta r}{2 r_{j+1}}\right)^{z} \frac{\Delta \tau}{\Delta r^{2}}, j=1, . ., m-1, \\
P_{j+1, j}^{k}=\frac{\lambda_{j+1}^{k}}{c_{j}^{k} \rho_{j}^{k}}\left(1+\frac{\Delta r}{2 r_{j}}\right)^{2} \frac{\Delta \tau}{\Delta r^{2}}, j=1, . ., m-1, \\
P_{j, j}^{k}=1-P_{j+1, j}^{k}-P_{j-1, j}^{k}, j=1, . ., m .
\end{gathered}
$$

В формулах (3),(4) выражения в круглых скобках учитывают переменность объемов ячеек в цепи и разные площади из контакта. Эти множители играют роль коэффициентов Лямэ в обобщенных координатах. Показатель степени $z$ адаптирует скобку к конфигурации домена. При $z=0$ формулы (3),(4) формируют матрицу теплопроводности для плоской стенки, при $z=1-$ для цилиндрического сектора, при $z=2$ - для шарового сектора. Таким образом, формулы (2)-(5) позволяют автоматически строить матрицу теплопроводности для любого из трех доменов, показанных на рис.1.

Цепь испытывает теплообмен с окружающей средой через внешнюю поверхность периферийной ячейки. Для его расчета необходимо знать распределение температуры по ячейкам, которое рассчитывается по формуле

$$
\mathbf{T}=\mathbf{Q} . / \boldsymbol{\rho} . / \mathrm{V} . / \mathbf{c},
$$

где оператор ./ означает поэлементное деление векторов.

В результате теплообмена в течение временного перехода запас теплоты во внешней ячейке с номером $m$ изменится

$$
Q_{m}^{k+1}:=Q_{m}^{k+1}+\alpha\left(T_{\text {out }}^{k+1}-T_{m}^{k+1}\right) S \Delta t,
$$

где $\alpha$ - коэффициент теплоотдачи, $T_{\text {out }}^{k+1}-$ температура окружающей среды, которая также может зависеть от времени, $S$ площадь внешней поверхности теплообмена, принимаемая равной единице.

После каждого перехода цепь проверяется на теплофизическое состояние ячеек $j=1 \ldots m$. Если $T_{j}^{k+1}<T_{j}^{k}$ (идет процесс охлаждения) и $T_{j}^{k+1}<T_{f r}\left(T_{f r}-\right.$ температура замерзания), но $M_{L j}^{k+1}=0 \quad$ (замерзание жидкости полностью завершилось), то температура $T_{j}^{k+1}$ не изменяется. В 
противном случае начинается или продолжается замерзание жидкости в ячейке. Выделяющаяся при этом в течение $\Delta t$ теплота рассчитывается по формуле

$$
\Delta Q_{f r j}^{k+1}=\left(T_{j}^{k+1}-T_{f r}\right) c_{j}^{k} \rho_{j}^{k} V_{j}
$$

Она идет на уменьшение массы жидкости или на увеличение замерзшей массы

$$
\Delta M_{L j}^{k+1}=\Delta Q_{f r}^{k+1} / q_{f r},
$$

где $q_{f r}$ - скрытая теплота замерзания. При этом температура ячейки остается постоянной и равной $T_{f r}$.

Таким образом, окончательно формируются векторы теплового и фазового состояния $\mathbf{Q}^{\mathrm{k}+1}, \mathbf{T}^{\mathrm{k}+1}$ и $\mathbf{M}_{\mathrm{L}}^{\mathrm{k}+1}$ после $k$-го перехода. Фазовое состояние удобно выразить относительной величиной

$$
\mathrm{m}_{\mathrm{L}}^{\mathrm{k}+1}=\mathrm{M}_{\mathrm{L}}^{\mathrm{k}+1} \cdot / \rho_{\mathrm{L}}^{\mathrm{K}+1} \cdot / \mathrm{V}
$$

Для расчета следующего перехода необходимо пересчитать теплофизические свойства сред в ячейках, входящие в формулы (3),(4). Если в данном состоянии фазовый переход происходит в ячейке с номером $n$, то при $j>n m_{L j}=0$, а при $j<n$ $m_{L j}=1$, то есть $n$ является границей разделения свойств твердой фазы и жидкой (в нашем случай льда и воды). По мере протекания процесса $n$ убывает от $m$ до 1 .

Таким образом, описанная выше модель позволяет не только описать распределенный процесс теплопроводности с фазовым переходом, но и учесть движение границы раздела фаз и его влияние на интегральные показатели процесса. Последнее представляет существенную новизну по сравнению с известными исследованиями.

Для определения физической непротиворечивости выполняемых с помощью разработанной модели расчетов и оценки еe прогностических возможностей была выполнена серия численных экспериментов, результаты которых приведены и обсуждаются ниже. Численные эксперименты выполнялись в среде MATLAB. Они выполнены для замерзания воды в цилиндрическом объеме радиусом $R=0.05 \mathrm{~m}$. Термическое сопротивление удерживающей объем оболочки (трубы) считалось достаточно малым, чтобы им можно было пренебречь. Теплофизические свойства фаз были приняты следующими: вода $\left(\rho_{L}=1000 \kappa г / \mathrm{m}^{3}, \quad c_{L}=4.2\right.$ кДж/кг. ${ }^{\circ} C, \lambda_{L}$ $\left.=0.556 \mathrm{BT} / \mathrm{M}^{\circ} \mathrm{C}\right)$; лед $\left(\rho_{S}=917 \kappa \Gamma / \mathrm{M}^{3}, c_{S}=2.09\right.$ $\mathrm{k}$ Дж/к $\left.\Gamma^{\circ} \mathrm{C}, \lambda_{S}=2.33 \mathrm{BT} / \mathrm{M}^{\circ} \mathrm{C}\right) ; \alpha=20 \mathrm{BT} / \mathrm{M}^{2 . \circ} \mathrm{C}$; скрытая теплота замерзания $q_{f r}=3.35 * 10^{5}$ Дж/кг. Число ячеек $m=10$ выбрано как компромисс между точностью и временем расчета.

Результаты моделирования показаны на рис.2-7. Рисунок 2 иллюстрирует эволюцию распределения температуры по радиусу домена.

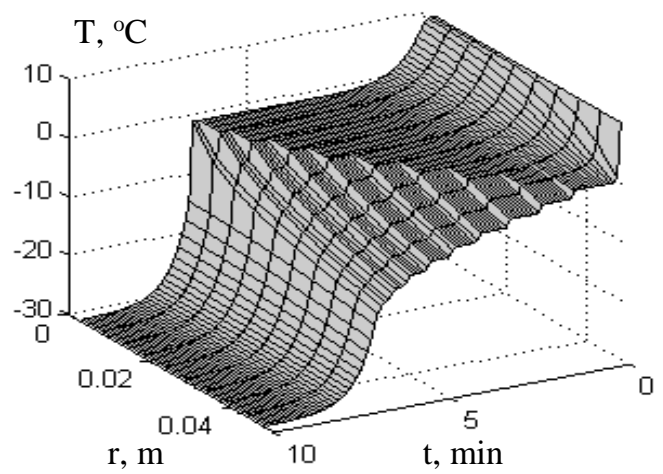

Рис.2. Эволюция распределения температуры по радиусу домена. ${ }^{2}$

Эволюция распределения относительного содержания жидкости вдоль домена показана на рис.3.

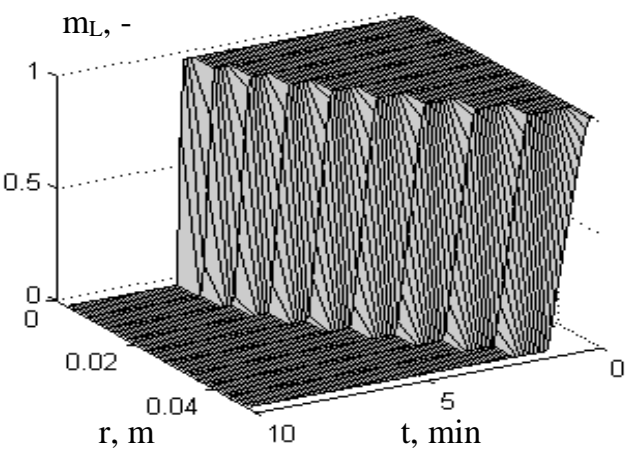

Рис.3. Эволюция распределения относительного содержания жидкой фазы по радиусу домена. ${ }^{3}$

Сначала весь домен охлаждается достаточно быстро до температуры

2,3 Appendix 1 
замерзания. После того, как в периферийной ячейке начался фазовый переход (замерзание жидкости), температура в ней остается постоянной до полного замерзания жидкости. В это время теплопередача между периферийной и следующей вглубь ячейкой отсутствует, так как между ячейками нет разности температур. После полного замерзания жидкости периферийная ячейка охлаждается как твердое тело, а фазовый переход начинается в следующей ячейке и так далее.

Исчезновение жидкой фазы ускоряется по мере продвижения границы раздела фаз к оси домена, так как объем ячеек при этом уменьшается (см. рис.1).

На рис.4 показаны кривые продвижения фронта замерзания вглубь домена при различном представлении свойств среды в описанной модели теплопроводности.

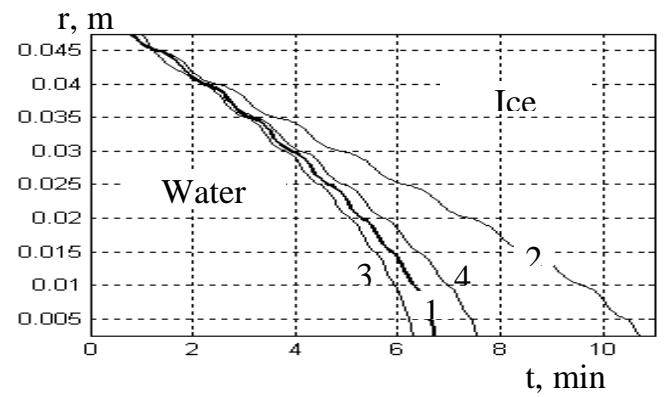

Рис.4. Фазовые диаграммы при различном представлении свойств среды. ${ }^{4}$

Кривая 1 рассчитана по модели, учитывающей продвижение границы радела фаз вглубь домена и скачка свойств среды на этой границе. Остальные кривые рассчитаны при одинаковых и постоянных теплофизических свойствах фаз, то есть без их скачка на границе: 2 - при теплофизических свойствах воды; 3 - при теплофизических свойствах льда; 4 - при их среднеарифметическом значении. Очевидно, что учет подвижности раздела фаз вносит вклад в расчет времени полного замерзания домена, однако степень повышение точности расчетного прогноза существенно зависит от разности свойств фаз и выбора базового варианта для сравнения. Так работа со свойствами кривой 2 завышает расчетный прогноз времени полного промерзания домена в 1.6 раза.

Рисунки 5,6,7 иллюстрируют возможности разработанной модели при переменной температуре окружающей среды. Через 5 мин с начала процесса эта температура скачком возвращается к $+10^{\circ} \mathrm{C}$. Начальное неполное промерзание домена сменяется на его прогрев и оттаивание, начинающееся с периферийной ячейки. На рис.5 показана эволюция распределения температуры до полного восстановления начального теплового состояния, на рис.6 - эволюция распределения относительного содержания жидкой фазы. Из рис.7 следует, что процесс оттаивания жидкости идет дольше, чем процесс ее замерзания.

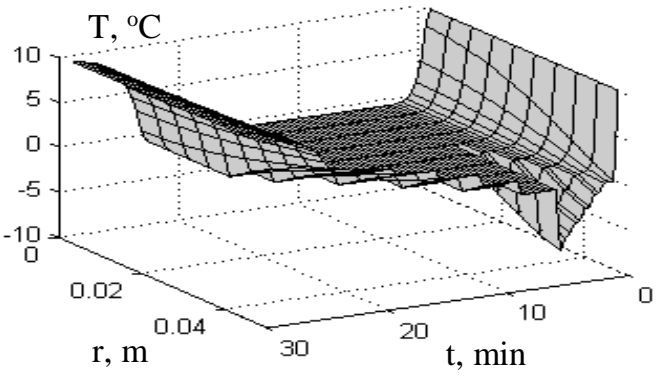

Рис.5. Эволюция распределения температуры по радиусу домена при скачке окружающей температуры. 5

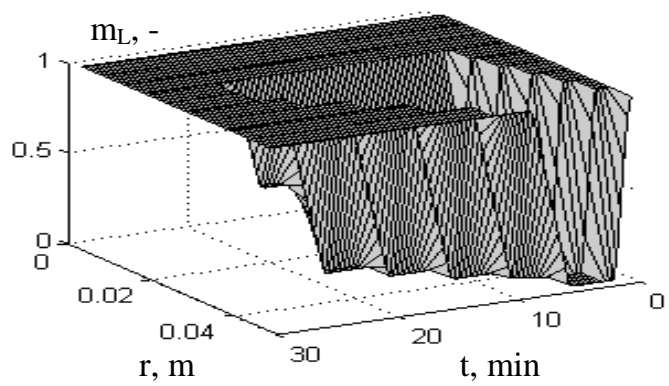

Рис.6. Эволюция распределения относительного содержания жидкой фазы при скачке окружающей температуры. ${ }^{6}$

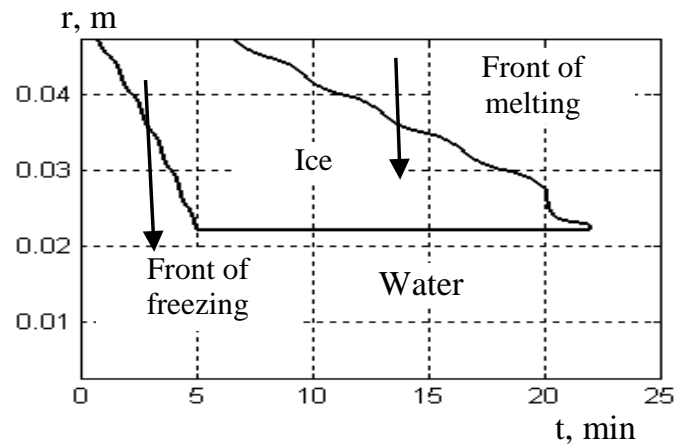

Рис.7. Фазовая диаграмма при скачке окружающей температуры. ${ }^{7}$

Это объясняется тем, что формирующийся при замерзании на периферии лед имеет 
большую теплопроводность, чем формирующаяся при оттаивании жидкость.

Bce графики полностью соответствуют физике процесса.

\section{ВЫВОДЫ}

1. Разработана нелинейная математическая модель теплопроводности в среде с фазовыми переходами, отличающаяся тем, что в ней учтено движение границы раздела фаз и скачка свойств среды на ней в объемах канонической формы: плоской стенке, цилиндре и шаре.

2. На примере замерзания жидкости в цилиндрическом объеме выполнено теоретическое исследование эволюции распределения теплового и фазового состояния среды при движущейся границе раздела фаз. Показано, что не учет движения границы раздела фаз может приводить к значительной ошибке в расчете времени полного замерзания жидкости, величина которой, однако, зависит от уровня различия теплофизических свойств фаз.

3. Приведен пример расчета кинетики процесса замерзания и оттаивания жидкости при переменной температуре окружающей среды. Показано, что процесс оттаивания продолжительнее процесса промерзания до одинаковой глубины.

\section{БЛАГОДАРНОСТЬ}

Исследование выполнено при финансовой поддержке Российского фонда фундаментальных исследований и Ивановской области в рамках научного проекта № 20-48-370001

\section{APPENDIX 1 (ПРИЛОЖЕНИЕ 1)}

1Fig.1. The volumes of canonic shape for modeling ( ( $\mathrm{a}$ - plane wall, $\mathrm{b}$ - cylinder, $\mathrm{c}-$ ball $)$ and the cell model structure (d).

${ }^{2}$ Fig.2. Evolution of temperature distribution over domain radius.

${ }^{3}$ Fig.3. Evolution of distribution of the relative content of liquid phase over domain radius.

${ }^{4}$ Fig.4. Phase diagrams for different presentation of the medium properties.

${ }^{5}$ Fig.5. Evolution of temperature distribution over domain radius at the outside temperature jump.

${ }^{6}$ Fig.6. Evolution of distribution of the relative content of liquid phase over domain radius at the outside temperature jump.

${ }^{7}$ Fig.7. Phase diagram at the outside temperature jump.

\section{Литература (References)}

[1] Lü X., Lu T., Viljanen M. A new analytical method to simulate heat transfer process in buildings. Applied Thermal Engineering, 2006, vol. 26, pp. 1901-1909.

[2] Maestre I.R., Cubillas P.R., Pérez-Lombard R. Transient heat conduction in multi-layer walls: An efficient strategy for Laplace's method. Energy and Buildings, 2010, vol. 42. pp. 541-546. https://doi.org/10.1016/j.enbuild.2009.10.023

[3] de Almeida A.P., Naveira-Cotta C.P., Cotta R.M. Transient three-dimensional heat conduction in heterogeneous media: Integral transforms and single domain formulation. International Communications in Heat and Mass Transfer, 2020, vol. 117, October, 104792

[4] Kong F., Zhang Q. Effect of heat and mass coupled transfer combined with freezing process on building exterior envelope. Energy and Buildings, 2013, vol. 62, pp. 486-495. https://doi.org/10.1016/j.enbuild.2013.03.012

[5] Ben-Nakhi A.E. Minimizing thermal bridging through window systems in buildings of hot regions. Applied Thermal Engineering, 2002, vol. 22, pp. 989-998. https://doi.org/10.1016/S13594311(01)00121-1

[6] Aguilar F., Solano J.P., Vicente P.G. Transient modeling of high-inertial thermal bridges in buildings using the equivalent thermal wall method. Applied Thermal Engineering, 2014, vol. 67, pp. 370-377.

https://doi.org/10.1016/j.applthermaleng.2014.0 3.058

[7] Ascione F., Bianco N., De Masi R.F., De' Rossi R., Vanoli G.P. Simplified state space representation for evaluating thermal bridges in building: Modeling, application and validation of a methodology. Applied Thermal Engineering, 2013, vol. 61, pp. 344-354,

https://doi.org/10.1016/j.applthermaleng.2013.0 7.052

[8] Belghazi H., El Ganaoui M., Labbe J.C. Analytical solution of unsteady heat conduction in a two-layered material in imperfect contact subjected to a moving heat source. International Journal of. Thermal Sciences, 2010, vol. 49, pp. 311-318.

[9] Winczek J. Analytical solution to transient temperature field in a half-infinite body caused by moving volumetric heat source, International Journal of Heat and Mass Transfer. 2010, vol. 53, pp. 5774-5781.

[10] Beckers J.-M. An anomalous non-linear heatconduction problem (improvement). Mathematical and Computer Modelling, 1990, vol.13, no. 5, pp. 89-92, https://doi.org/10.1016/0895-7177(90)90045-O.

[11] Campo A., Macia Y.M., Sieres J. Semianalytical solution of unsteady heat conduction in plain walls with equal surface temperatures: The transversal method of lines (TMOL) delimited to thesmall all time" sub-domain. Interna- 
tional Communications in Heat and Mass Transfer, 2020, vol. 116, July, 104687.

[12] Hao-Yang Li, Geng-Hui J., Kai Y., Xiao-Wei G. A new approach to solve multi-medium nonlinear transient heat conduction problems using interface integration BEM. Engineering Analysis with Boundary Elements, 2020, vol. 119, October, pp. 269-279.

[13] Agarwala S., Prabhu K.N. An experimental approach based on inverse heat conduction analysis for thermal characterization of phase change materials. Thermochimica Acta, 2020, vol. 685, March, 178540.

[14] Zhang B., Mei J., Zhang Y. A general approach for solving three-dimensional transient nonlinear inverse heat conduction problems in irregular complex structures. International Journal of Heat and Mass Transfer, 2019, vol. 140, September, 2019, pp. 909-917.

[15] Zhou X., Sun D., Xu Y. A new thermal analysis model with three heat conduction layers in the nuclear waste repository. Nuclear Engineering and Design, 2021, vol. 371, 110929.

[16] Aniruddha B., Weizhong D. Gradient preserved method for solving heat conduction equation with variable coefficients in double layers. $A p$ plied Mathematics and Computation, 2020, vol. 386, no.1, 125516.

[17] Qu W., Fan C-M., Zhang Y. Analysis of threedimensional heat conduction in functionally graded materials by using a hybrid numerical method. International Journal of Heat and Mass Transfer, 2019, vol. 145, December, 118771.

[18] Shi X., Wang Q., Wang L. New Galerkin-vector theory and efficient numerical method for analyzing steady-state heat conduction in inhomo-

\section{Сведения об авторах.}

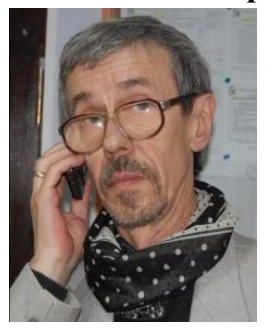

Мизонов Вадим Евгеньевич, доктор технических наук, Ивановский государственный энергетический университет,. Область научных интересов: применение теории цепей Маркова в химической инженерии. E-mail: $\underline{\text { mizonov46@mail.ru }}$

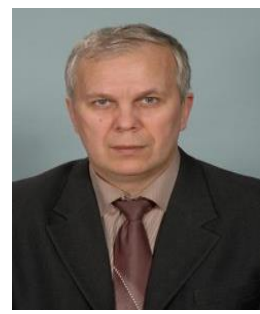

\section{Тихонов Андрей Иль-}

ич, доктор технических наук. Область научных интересов: технологии порождающего проектирования, цифровые двойники проектируемых объектов.

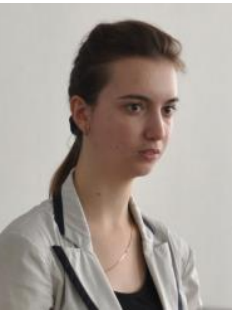

Басова Елена Владимировна, аспирант, Ивановский государственный энергетический университет. Область научных интересов: моделирование нелинейных процессов переноса.

E-mail: nowikowa.elena@mail.ru

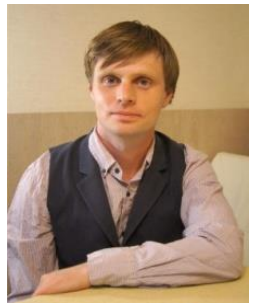

Митрофанов Андрей Васильевич, доктор технических наук. Область научных интересов: процессы в кипящем слое. E-mail: and2mit@mail.ru 